\title{
A study on the effectiveness of Personal Protective Equipment (PPE) on Building Construction Workers
}

\author{
Lu Rong Guan ${ }^{1}$, Goh Jun Xian ${ }^{1}$, Salini Devi Rajendran ${ }^{1 *}$, and Siti Norida Wahab ${ }^{1}$ \\ ${ }^{1}$ Faculty of Business and Information Science, UCSI University, Jalan Menara Gading, 56000 Cheras, Kuala Lumpur, Malaysia.
}

\begin{abstract}
Nowadays, Occupational Safety and Health has getting more important in Malaysia. Personal Protective Equipment (PPE) is one of the way to protect building construction workers, PPE is any equipment, device or material that worn or used by the workers to protect them from exposure or contact with any harmful material which may cause injury, disease or even death. Despite its benefits, the awareness of PPE is low among building construction workers. The purpose of this study is to examine the utilization of PPE and how the knowledge of using PPE affecting the safety of the workers on building construction. There are 100 workers from the building construction industry who participated in the survey. The data were collected using self-designed questionnaires and analyzed using partial correlation and multiple regression analysis. The obtained result reveals that awareness and training have positive effect while experience has negative effect toward the effectiveness on PPE on the construction workers.
\end{abstract}

\section{INTRODUCTION}

The Theory of reasoned action (TRA) assumes that behavioral intention is the directly determinant of behaviors and all of the factors that influencing particular behaviors that solved through intention [1]. The TRA has been applied with abundant achieve to a number of health behaviors, including PPE use, weight loss and exercise [2].

Personal protective equipment (PPE) is equipment that is worn by the workers to protect them from chemicals, physical impacts, fire and minimizes exposure to specific hazards [3]. Personal protective equipment (PPE) includes safety glasses, hearing protection, hard hats, protective gloves, fall protection equipment, respirators and full body suits. Although personal protective equipment (PPE) does not decrease the hazard itself and does not ensure total protection of workers, using PPE is considered as an important way for protecting the safety and health of workers.

The selection of Personal Protective Equipment must meet the requirement of the work. Beside that it must consider the methods of work, the physical effort requirement of work, the time of PPE needs to worn. The aim should always focus on the comfort level of the workers/ user. Discomfort equipment can see like it using wrongly or worn improperly. There have a better utilization if the equipment is accepted by all of the workers (Department of Occupational Safety and Health, 2003). This makes it very important to select the right suppliers to supply PPE of the appropriate grade to workers according to the industry.
Study on the awareness and use of PPEs among workers in funeral homes in Lagos State found out that some workers $(50 \%)$ had good knowledge about PPEs though the utilization of the same was low thus exposing them to workplace hazards [4]. The PPE shall be suited to the working environmental and properly selected for each workers and task, functional, clean and readily available, correctly used when it is required and maintained by appropriately trained workers in match with PPE servicing and maintained programs. These programs should be developed from manufacturers' recommendation in regard to servicing the equipment, if required [5]. The lack of training on safety and health issues causes lower awareness of safety which would make staff be more vulnerable to injury, thus low safety and health performance $[6,7]$.

According to the Malaysia Social Security Organization (SOCSO) secondary data, it shows that 2,822 case of occupational injuries in Malaysia with an average rate of 9.2 fatal injuries per 100,000workers. Department of Occupational Safety and Health (DOSH) had release the data recently, there are 1,116 accidents occur between 2011-2016 and 37.85\%-51.50\% of accident resulting death, permanent disability and nonpermanent disability occurred in building construction [8].

In year 2016 , more than $40 \%$ of the accidents are happened due to the fact that the workers did not wear personal protective equipment properly, one of the reason is because of the shortage of PPE and the other is due to the lack of knowledge of safety on PPE of the workers, such as lack of training or awareness [9]. And other $60 \%$ accidents are happened due to unique nature of industry, job condition, management problem and

\footnotetext{
*Corresponding author's e-mail: salinidevi@ucsiuniversity.edu.my
} 
Human element [9]. Besides that, experience of workers also will directly influence the effectiveness and utilization of PPE. According to Opeyemi samuel, most experienced workers will feel that PPE is not as important to them as they are already used to what they are doing. On the other hand, workers that are new to the specific field would think that PPE is important to them as it can protect them from getting injured [9]. Therefore, the purpose of this study is to examine the useful of PPE and how the knowledge of using PPE affects the safety of the workers on building construction.

\section{METHODOLOGY}

The quantitative method is used in this research to find out the relationship between dependent variable (DV) and indecent variables (IV). At the same time, the data will collect for once and over a period of few weeks, it is call as a cross-sectional study. This study is categorized as non-contrived study as the study is done in the natural environment where work proceeds normally and without any artificial settings.

\subsection{Hypothesis}

H1: Level of awareness of workers has negative effect to the effectiveness of PPE for building construction workers.

$\mathrm{H} 2$ : Level of training of workers has negative effect to the effectiveness of PPE for building construction workers.

H3: Experience of workers has negative effect to the effectiveness of PPE for building construction workers.

\subsection{Data collection method}

The primary data of this study is gathered from survey, where the questionnaire is distributes to the workers who are in the building construction area [10-13]. The secondary data is obtained from the previous work done such as published article and journal which serve as guidelines and references for this study.

\subsection{Sampling Design}

\subsubsection{Target Population}

In this study, the target population is the building construction workers working in Kuala Lumpur.

\subsubsection{Sampling Size}

The population of building construction workers in Kuala Lumpur is about 400,000workers [14]. The estimated respondents for this study will be about 384 workers because according to Krejcie and Morgan [15] when the target population is more than 250,000, it required 384 of sample size.

\subsubsection{Sampling Location}

The location is set in Kuala Lumpur building construction area. The questionnaire will be distributed to any workers in building construction area.

\subsubsection{Sampling Technique}

Quota sampling is choose to be the sampling technique because it can more easily to administer, create and complete and can be used when non-probability sampling. It is a non-probability sampling technique which the sample has same proportion of individual as the entire population with same traits, focus phenomenon and characteristics.

\subsection{Research Questionnaire}

The questionnaire is divided to three sections which are section A, B and C. Section A consists of social demographic profile. Section B consists of the questions about the level of awareness, level of training and experience of workers. Section $\mathrm{C}$ consists about the effectiveness of building construction workers.

The respondent is required to answer all the questions that show in questionnaires. Besides that, respondents need to rate from range $1-5$, that means the range is from strongly disagree to strongly agree. In another word: 1strongly disagree, 2- disagree, 3-neutral, 4-agree, 5strongly agree [16, 17]. Nominal scale is used to categorize the objects individual into mutually exclusive categories, one object or individual can only belong to one category with no repeat.

\subsection{Data Analysis}

Data analysis is the process to evaluate the collected data in the by using logical and statistical technique. IBM SPSS Statistics Software will be used to analyze data. Results created from IBM SPSS Statistics Software would be tabulated into histogram, statistical tables and other information

\subsubsection{Descriptive Analysis}

Descriptive analysis is the procedure of summarizing and interprets all the raw data collected into interpret the tables and the charts which can be interpreted. Besides that, median, mean and standard deviation of the independent variables in this research will be calculated to comprehend central tendency of the data. Descriptive analysis is used to analyze demographic information of the interviewee.

\subsubsection{Normality Test}

Normality test is utilize to make data is free from outlier. Moreover, it is used to obtain the skewness and kurtosis of the set of the collected data. The result of skewness is in a range between +2 to -2 . Besides, the result of 
Kurtosis should be less than 7 if the data is normally distributed [18].

\subsubsection{Reliability Test}

Reliability test is conducted to confirm all the data collected are precise, static and consistent. Results can be gained through the set of data. Cronbach's alpha will be used in this study to measure the consistency among the variety items in the test. IBM SPSS Statistical Software will compute the correlation coefficient value for each variable ranging from 0 to 1 . Higher reliability is represented by a larger value. Value of $>0.6$ is considered as acceptable range and value more than 0.80 is considered as very good reliability.

\subsubsection{Correlation Test}

Pearson product-moment correlation coefficient will be carried out in this study to judge and decide the strength of a linear association between two variables. The intensity of association and significance of relationship between the independent variables (IV) and dependent variables (DV) will be identified through this test. Pearson correlation coefficient, can take a range of values from +1 to -1 .

\subsubsection{Multiple Linear Regressions}

This test is applied in this survey to find out the relationship between the dependent variables (DV) and independent variables (IV). Besides, multiple linear regression is used to examine the strength of relationships for the overall regression model.

\subsection{Pilot Study}

Pilot study does happen when reduced scale is used and it is also known as a handy study [19]. It is used to monitor and supervise how a group of chosen people from the survey population makes their respective responds to the questionnaire. By using this pilot test, the effectiveness of Personal Protective Equipment (PPE) for building construction workers in Malaysia, the replies given by the respondents and probably make some changes to the questionnaire. After the amendments are made based on the comments made by them, the replies received from the questionnaires will be much more accurate and clear. As a result, there won't be any unreliable data.

\section{RESULT AND DISCUSSION}

The questionnaire was hand in to the construction workers living who are in Malaysia. The response rate which is 100 sets of survey questionnaire received from the workers of building construction industry in Malaysia.

\subsection{Reliability Test}

If the Cronbach's Alpha Value of the item tested is closer to 1.000 , it shows that the test is better. Table 1 shows Cronbach's alpha value for independent variable Awareness factor is 0.872 , Training is 0.871 , and Experience is 0.833 . The Cronbach's alpha value for dependent variable regarding Effectiveness of PPE has a value of 0.764 after conducting the test. The independent variable on Awareness gets the highest value compare to other independent variables and dependent variable.

Table 1. Cronbach's Alpha Value for Both Independent and Dependent Variables

\begin{tabular}{cc}
\hline Factors & Cronbach's Alpha \\
\hline Independent Variable - Awareness & 0.872 \\
Independent Variable - Training & 0.871 \\
Independent Variable - Experience & 0.833 \\
Dependent Variable - Effectiveness of PPE & 0.764 \\
Overall & 0.835 \\
\hline
\end{tabular}

\subsection{Normality Test}

According to the Normality Test for Both Independent and Dependent Variable in Table 2, the skewness and kurtosis for independent variable Awareness is -1.218 and 0.774. Furthermore, the skewness and kurtosis of Training is -1.1015 and 0.544 . The independent variable Experience's skewness and kurtosis has a value on 0.569 and -0.086 . Lastly, the dependent variable of Effectiveness of PPE, the skewness and kurtosis value is -1.045 and 0.701 .

Table 2. Normality Test for Both Independent and Dependent Variables

\begin{tabular}{llcccc}
\hline Variables & & \multicolumn{2}{c}{ Skewness } & \multicolumn{2}{c}{ Kurtosis } \\
\cline { 3 - 6 } & & Statistic & Std. Error & Statistic & Std. Error \\
\hline Independent Variables & Awareness & -1.218 & 0.241 & 0.774 & 0.478 \\
& Training & -1.015 & 0.241 & 0.544 & 0.478 \\
& Experience & -0.569 & 0.241 & -0.086 & 0.478 \\
\hline Dependent Variables & Effectiveness Of PPE & -1.045 & 0.241 & 0.701 & 0.478 \\
\hline
\end{tabular}

Figure 1 shows that the skewness and kurtosis value for awareness was -1.218 and 0.774 . Figure 2 shows that the skewness and kurtosis value for training was -1.1015 and 0.544 . Figure 3 shows that the skewness and kurtosis 
value for experience was -0.569 and -0.086 . Figure 4 shows that the skewness and kurtosis value for effectiveness of PPE was -1.045 and 0.701 . Since the

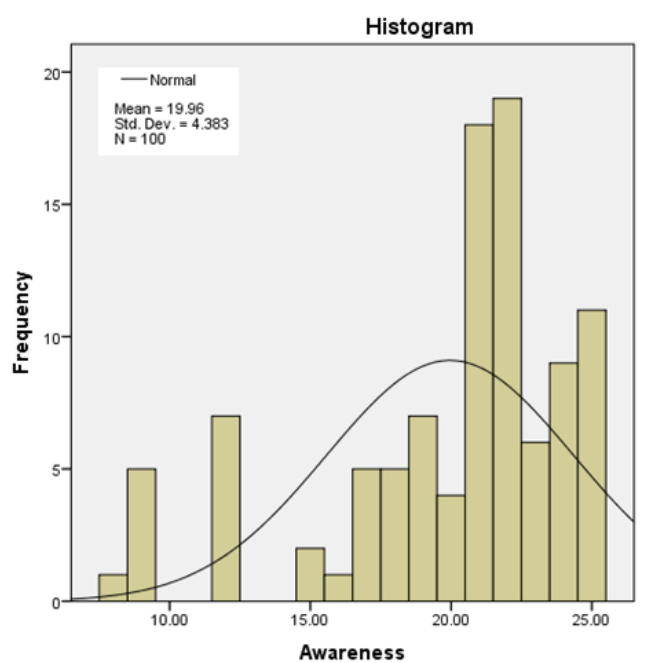

Figure 1. Normality test on Awareness

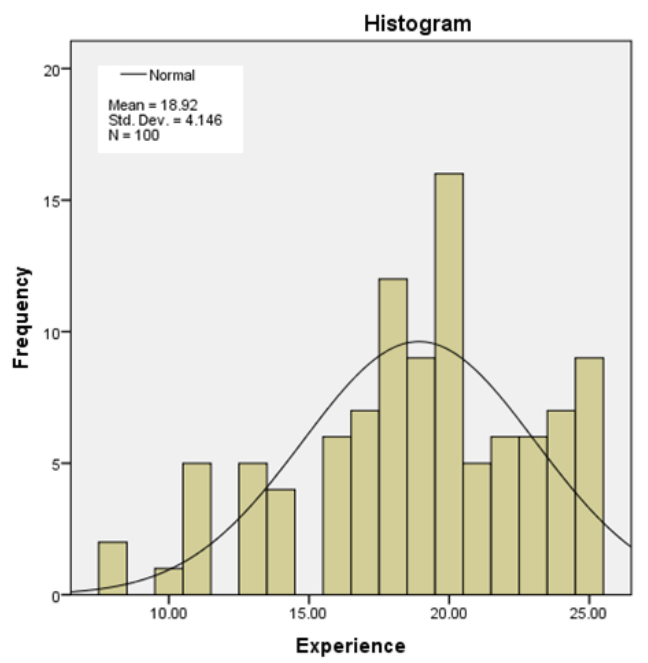

Figure 3. Normality test on Experience

\subsection{Descriptive Analysis}

Table 3 shows majority about 91 respondent answer that Protective Clothing and Head Protection used in construction industry, which means is it is common used in construction industry. Then, follow by the second highest PPE used in construction industry is Fall Protection, 74 respondents answer that it been used in the data are within the range between -2 and +2 , it is view as a normal distribution.

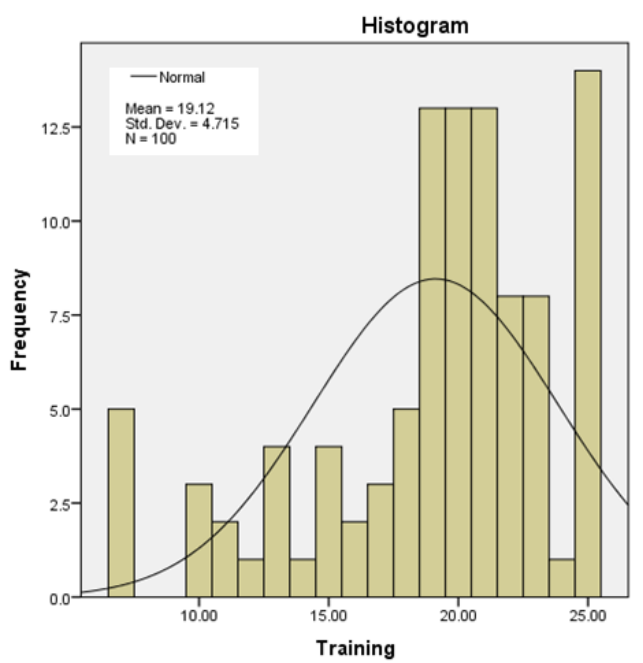

Figure 2. Normality test on Training

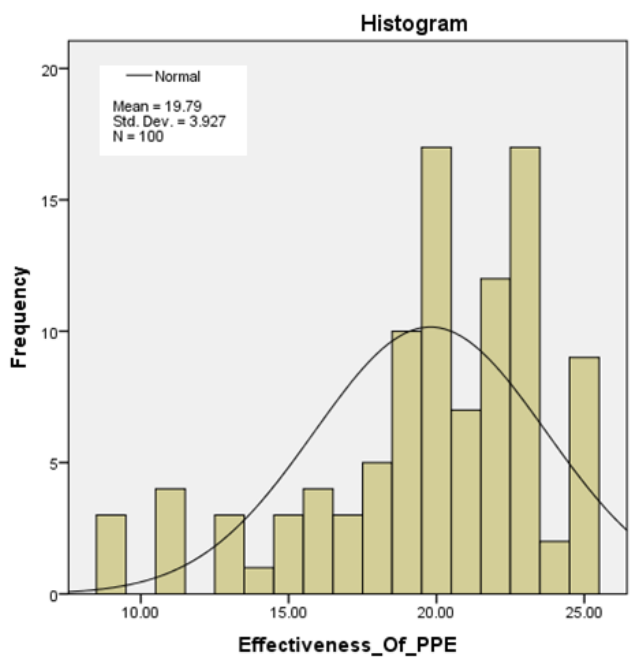

Figure 4. Normality test on Effectiveness of PPE industry. Next, Feet and Legs Protection and Eye Protection had the same number of respond answer which is known by 69 respondents. 68 respondents answered that hands protection were used in the industry, 58 respondents say they are using Ear Protection, 54 respondents used Nose Protection, and 52 respondents said that they using respirators. There are no respondents answer that there is any others PPE they know.

Table 3. Types of PPE used in industry

\begin{tabular}{cc}
\hline Types of PPE used in industry & Frequency \\
\hline Protective Clothing & 91 \\
Respirators & 52 \\
Eye Protection & 69 \\
Nose Protection & 54 \\
Ear Protection & 58 \\
Hands Protection & 68 \\
Feet and Legs Protection & 69 \\
Head Protection & 91 \\
Fall Protection & 74 \\
Others specify & 0 \\
\hline
\end{tabular}


Construction workers will use more than 1 PPE when they are working in the construction industry. Table 4 shows 91 respondent answer that they have Protective Clothing, only 5 respondents said they have Respirators, 24 respondents say that they have Eye Protection, 12 respondents answered that they have Nose Protection, 17 respondents said that they have Ear Protection, 31 respondents said that they have Hands Protection, 34 respondents said they have Feet and Legs Protection, 87 respondents answered they have Head Protection and Lastly, 32 respondents said they have Fall Protection. There are no respondents answered about any others PPE that they have.

Table 4. Types of PPE respondent have in industry

\begin{tabular}{cc}
\hline Types of PPE respondent have in industry & Frequency \\
\hline Protective Clothing & 91 \\
Respirators & 5 \\
Eye Protection & 24 \\
Nose Protection & 12 \\
Ear Protection & 17 \\
Hands Protection & 31 \\
Feet and Legs Protection & 34 \\
Head Protection & 87 \\
Fall Protection & 32 \\
Others specify & 0 \\
\hline
\end{tabular}

Table 5 shows about 9 of the respondents get PPE with borrowed from their friends or senior, 67 of respondents get PPE which provided by their employer.
Then, 24 of the respondents bought PPE by themselves. Lastly, there are no respondents giving others specify answer in the way of respondents getting PPE.

Table 5. Ways of respondents getting PPE

\begin{tabular}{cc}
\hline Ways of Respondents Getting PPE & Frequency \\
\hline Borrowed & 9 \\
Provided by Employer & 67 \\
Bought themself & 24 \\
Others Specify & 0 \\
\hline
\end{tabular}

Table 6 shows that 81 of the respondents used PPE when they are on duty always, 12 respondents answered that they used PPE when supervisor is around, and only 7 respondents said that they used PPE when they feel like so. Lastly, there are no respondents giving others specify answer in when they use PPE.

Table 6. Time of respondents using PPE

\begin{tabular}{cc}
\hline Time of respondents using PPE & Frequency \\
\hline When on duty always & 81 \\
When supervisor is around & 12 \\
When I feel like so & 7 \\
Others Specify & 0 \\
\hline
\end{tabular}

Besides that, about $54 \%$ of respondents have PPE if they suffered injuries or illness that associate by construction. And $46 \%$ of respondents did not have any PPE if they suffer any injuries or illness. It is means that some of the respondents will not have PPE if they did not suffer from injuries or illness before.

\subsection{Partial Correlation Coefficient Test}

Partial Correlation is used to identify the linear relationship's strength and direction of degree between two continuous variables. It removes the influence of third variable in order to give a clear picture of the actual relationship between two variables and also explain that linear relationship can be characterized by straight line. The Partial Correlation Coefficient test value must be within the range of -1 and +1 . It shows a negative relationship between the variable if the number is between -1 and 0 . A positive relationship between the variable will be present if the value fall between 0 and +1 . If the value shows 0 it is means that there is no relationship exists between the variable [20].

\subsubsection{Relationship between Awareness, Training, Experience and Effectiveness of PPE}

Table 7 shows the correlation on the relationship between the Awareness, Training, Experience and Effectiveness of PPE. It shows a positive correlation between awareness and effectiveness of PPE ( $r=0.733$, $r>0.1$ ). It shows a positive correlation between training and effectiveness of PPE $(r=0.758, r>0.1)$. It shows a positive correlation between experience and effectiveness of PPE $(r=0.677, r>0.1)$. This indicates that 
the relationship between awareness, training, and experience has a strong relationship toward the effectiveness of PPE which means that the training is useful and it is affecting the strength of relationship between training and effectiveness of PPE. Also, when the data in Sig 2-tailed level show .000, it means that the relationship between the independent variable and dependent variable are strong.

Table 7. Partial Correlation on the Relationship between Awareness, Training, Experience and Effectiveness of PPE

\begin{tabular}{lccccc}
\hline & Control Variable & Aware & Train & Exp & Effect \\
\hline Awareness & Correlation & 1.000 & .797 & .697 & .733 \\
& Sig. (2-tailed) &. & .000 & .000 & .000 \\
& $\mathrm{~N}$ & 100 & 100 & 100 & 100 \\
\hline Training & Correlation & .797 & 1.000 & .809 & .758 \\
& Sig. (2-tailed) & .000 &. & .000 & .000 \\
& $\mathrm{~N}$ & 100 & 100 & 100 & 100 \\
\hline Experience & Correlation & .697 & .809 & 1.000 & .677 \\
& Sig. (2-tailed) & .000 & .000 &. & .000 \\
& $\mathrm{~N}$ & 100 & 100 & 100 & 100 \\
\hline Effectiveness of PPE & Correlation & .733 & .758 & .677 & 1.000 \\
& Sig. (2-tailed) & .000 & .000 & .000 & 100 \\
& $\mathrm{~N}$ & 100 & 100 & & 100 \\
\hline
\end{tabular}

Note: **. Correlation is significant at the 0.01 level (2-tailed).

\subsection{Multiple Regression Analysis}

Table 8 shows R2 is 0.626 with the Adjusted R2 of 0.614 , which means the linear regression are able to explain
$62.6 \%$ of the variation on the data, and $61.4 \%$ can be explained. Moreover, the $\mathrm{R}$ value represent the simple correlation is 0.791 , which indicates that there is a high level degree of correlation between independent and dependent variable.

Table 8. Model Summary of Regression Analysis

\begin{tabular}{ccccc}
\hline Model & $\mathrm{R}$ & R Square & Adjusted R Square & Std. Error of the Estimate \\
\hline 1 & $.791^{\mathrm{a}}$ & .626 & .614 & 2.43898 \\
\hline a. Predictors: (Constant), Experience, & Awareness, Training & \\
\hline
\end{tabular}

Table 9 shows the largest beta coefficient is 0.386 , which is Training variables. This means that the independent variable (Training) makes the strongest unique to explain dependent variable. Beta value for Experience variable was the lowest 0.132 show that it made a less unique contribution but still have contribution on explaining dependent variable. Then, the variables of Awareness and Training, which the significant value that less that 0.05 variable. It is means that the variables of Awareness and Training making a significant contribution on the prediction of dependent variables. For the variables Experience, it shows that the significant value which is more than 0.05 , which means that this variable are not making a significant unique contribution to the prediction of dependent variable. This is because the workers feels that no matters there have experience or not, PPE is an important stuff for the workers to used when they are working on construction area. Lastly, the independent factors of Awareness and Training have a Sig value of less than 0.05 which indicates that it is a positive and strong relationship between dependent and independent variable.

Table 9. Coefficients in Regression Analysis

\begin{tabular}{llccccc}
\hline \multirow{2}{*}{ Model } & \multicolumn{2}{c}{ Unstandardized Coefficients } & Standardized Coefficients & \multirow{2}{*}{ t } & \multirow{2}{*}{ Sig. } \\
\cline { 2 - 5 } & & $\mathrm{B}$ & Std. Error & Beta & & \\
\hline 1 & (Constant) & 5.321 & 1.244 & .276 & .000 \\
& Awareness & .298 & .094 & .333 & 3.191 & .002 \\
& Training & .321 & .106 & .386 & 3.028 & .003 \\
& Experience & .125 & .102 & .132 & 1.229 & .222 \\
\hline
\end{tabular}

The multiple regression equation is $\gamma=5.321+0.298$ $($ Awareness $)+0.321$ (Training) +0.125 (Experience $)+$ 1.244

Table 10 shows the significant value is 0.000 $(\mathrm{p}=.000)$, which means it is below the significant level of $0.05(p<.05)$. So that it indicates that there is a significant difference among the mean score on dependents variable and groups as determined by ANOVA $\{\mathrm{F}=53.543$, $\mathrm{p}=.000 \mathrm{p}\}$. Thus, the following hypothesis was supported:
H1: Level of awareness of workers has positive effect to the effectiveness of PPE for building construction workers.

$\mathrm{H}$ 2: Level of training of workers has positive effect to the effectiveness of PPE for Building Construction Workers.

The study fails to reject the null hypothesis for the following 
H3: Experience of workers has negative effect to the effectiveness of PPE for building construction

workers.

Table 10. Result of ANOVA Analysis

\begin{tabular}{lcccccc}
\hline Model & Sum of Squares & $\mathrm{df}$ & Mean Square & $\mathrm{F}$ & Sig. & Model \\
\hline 1 & Regression & 955.521 & 3 & 318.507 & 53.543 & $.000 \mathrm{~b}$ \\
& Residual & 571.069 & 96 & 5.949 & & \\
& Total & 1526.590 & 99 & & & \\
\hline
\end{tabular}

a. Dependent Variable: Effectiveness of PPE

b. Predictors: (Constant), Awareness, Training, Experience

\section{CONCLUSION}

The utilization of personal protective equipment for construction workers is measured by three independent variables namely awareness, training and experience. The obtained result shows that the each of the independent variable is affected from the dependent variable which is the effectiveness on PPE on the construction workers. Majority of the construction workers feel that awareness is important elements that affecting the effectiveness of PPE. Then, the workers must have training on PPE equipment before they start using the PPE in construction site to increase the effectiveness. The experience of workers does not affect the effectiveness of PPE because the workers must wear PPE equipment while they are in construction site to protect themselves from injuries.

\section{References}

1. Ling E.K. \& Wahab, S.N. (2018). Integrity of Food Supply Chain: Going beyond Food Safety and Food Quality. International Journal of Productivity and Quality Management, DOI: 10.1504/IJPQM.2019.10019297.

2. Cleary, P. (1987). Why people take precautions against health risks. IND Weinstein (Ed.) Taking care: Understanding and encouraging self-protective behaviour (pp. 119-149).

3. Sutton (2017), Plant and Design and operations (second edition): Personal Protective Equipment, 401-415.

4. T.S. Oguntona, O.O. Adedeji, DebayoOgunsola. Awareness and Use of Personnel Protective Equipment (Ppe) and Practice of Safety Precautions among Funeral Home Workers In Lagos State. Transnational Journal of Science and Technology October 2012 edition vol.2, No. 9.

5. Taylor N, Lewis M, Notley S, and Peoples G. A fractionation of the physiological burden of the personal protective equipment worn by firefighters. European Journal of Applied Physiology 112: 29132921, 2012.

6. V. W. Y. Tam and I. W. H. Fung, 2008, A Study of Knowledge, Awareness, Practice and Recommendations Among Hong Kong Construction Workers on Using Personal Respiratory Protective Equipment at Risk, The Open Construction and Building Technology Journal, 2008, 2, 69-81.
7. Marc B. Schenker, Marla R. Orenstein and Steven J. Samuels. Use of Protective Equipment among California Farmers. American Journal of Industrial Medicine 42:455-464 (2002)

8. Nor Haslinda Abas (2017) Causes of Fatal Accidents Due to Fall of Persons in Malaysian Construction Industry

9. Opeyemi Samuel, W. (2017). Analysis of Fatal Building Construction Accidents: Cases and Causes.

10. Wahab, S.N., Rajendran, S.D., Yeah N.K., \& Deng Y. (2017). Antecedents Influencing E-Service Quality towards Customer Loyalty among Malaysian Online Shoppers. 3rd International Conference on Advanced Research in Business and Social Sciences, 29-30 March, 337-346, Langkawi Malaysia.

11. Sham, R., Wahab S.N., \& Hussin, A.A.A. (2018). Smart Trolley Apps: A Solution to Reduce Picking Error. International Journal of Supply Chain Management, 7(5), pp. 294-302.

12. Wong, C.H., Tan, G.W.H., Tan, B.I and Ooi, K.B. (2015). Mobile Advertising: The Changing Landscape of the Advertising Industry', Telematics and Informatics, Vol. 32 No.4, 720-734.

13. Wahab, S.N., Sham, R., Hussin, A.A.A, Ismail, S., \& Rajendran, S.D. (2018). Urban Transportation: An Analysis on Bike Sharing Usage in Klang Valley. International Journal of Supply Chain Management, 7(5), 470-476.

14. Amarjit Kaur (2014) Managing Labour Migration in Malaysia: Guest Worker Programs and the Regularisation of Irregular Labour Migrants as a Policy Instrument, Asian Studies Review, 38:3, 345-366, DOI: 10.1080/10357823.2014.934659

15. Krejcie, R.V., \& Morgan, D.W., (1970). Determining Sample Size for Research Activities. Educational and Psychological Measurement.

16. Chong, J. L., Chong, A. Y. L., Ooi, K. B., \& Lin, B. (2011). An empirical analysis of the adoption of $\mathrm{m}$ learning in Malaysia. International Journal of Mobile Communications, Vol. 9 No.1, 1-18.

17. Rajendran, S.D., Wahab, S.N, Ling, Y.W., and Yun, L.S. (2018). The Impact of Logistics Services On the E-Shoppers' Satisfaction, International Journal of Supply Chain Management, 7(5), pp. 461-469.

18. Wahab, S.N., Lay, Y.F., Koay, W.L., \& Hussin, A.A.A, (2019). Usage of Pedestrian Bridge among the Urban Commuters in Kuala Lumpur. International Journal of Operational Research, DOI: 10.1504/IJOR.2021.10019276.

19. Polit, Denise F., Cheryl Tatano Beck, and 
Bernadette P. Hungler. 2001. Essentials of nursing research: methods, appraisal, and utilization. Philadelphia: Lippincott.

20. Saunders, M., Lewis P., \& Thornhill, A. (2009). Research Methods for Business Students (5thedition). New Jersey: Prentice Hall. 